\title{
Hodgkin's disease in adults: The challenge
}

\author{
T.A. Lister \\ ICRF Department of Medical Oncology, St Bartholomew's Hospital, London ECIA 7BE, UK.
}

It is now without dispute that the majority of patients with Hodgkin's disease, presenting to a referral centre will be alive, most of them without evidence of disease, ten years later. This may be illustrated by the results from St Bartholomew's Hospital, which are very similar to those from other major centres. Three hundred and ninety one out of five hundred and three adults referred for initial therapy between 1968 and 1983 are alive in 1984 , two hundred and eighty three without recurrence with a median follow up of six years, and seventy per cent predicted alive at ten years. This is a remarkable feat, achieved as a result of improvements in radiation technique, the requirement for which was hinted at from St Bartholomew's Hospital in 1916 (Finzi, 1913) and pioneered in Switzerland, Canada and the United States (Gilbert, 1939; Peters, 1950; Kaplan, 1962), and the subsequent development of combination chemotherapy at the National Cancer Institute, Bethesda (De Vita et al., 1970).

\section{Causes of death in Hodgkin's disease}

It remains, however, true that at least a fifth, and possibly even a third of patients presenting with Hodgkin's disease will die prematurely. The major problem, therefore, facing those investigating the treatment of Hodgkin's disease is to reverse this situation, all other problems being of lesser importance. Overwhelmingly the most important reason why perhaps one third of patients presenting with Hodgkin's disease are dead within ten years is the disease itself, although second malignancy and infection, especially in those who have received multiple therapy contribute increasingly with prolonged follow up. The causes of death in the patient population at $\mathrm{St}$ Bartholomew's Hospital referred to above are shown in Table I from which it may be seen that sixty eight per cent died with active Hodgkin's disease.

Achievement of complete remission with the initial therapy is the first and greatest pre-requisition for prolonged survival, only anecdotal patients living longer otherwise (Figure 1). Recurrence following chemotherapy, which post treatment laparotomy studies show may be the result of failure to eradicate clinically undetectable residual disease in the spleen (Sutcliffe et al., 1982), almost certainly means death in the short term regardless of whether second remission is achieved. Although 'salvage' chemotherapy for patients in whom recurrence occurs after radiotherapy-induced remission yields second complete remission in a high proportion of cases (Canellos et al., 1972; Timothy et al., 1978), survival thereafter may be towards fifty per cent at eight years (T.A. Lister, unpublished observations).

The immediate goals consequently, are to identify those patients at high risk of either failure to achieve complete remission, or to relapse, and to develop more appropriate treatment strategies for them. In the light of the current ignorance of the biology of the disease it is likely that improved treatments will, at least in the

Table I Causes of death in 112 of 503 patients with previously untreated Hodgkin's disease

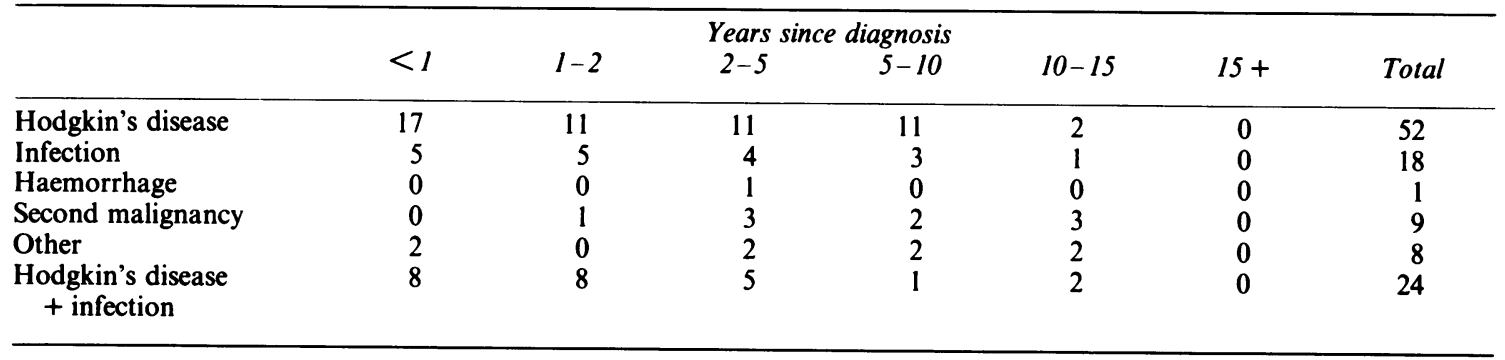

T.A. Lister, M.D., F.R.C.P. 


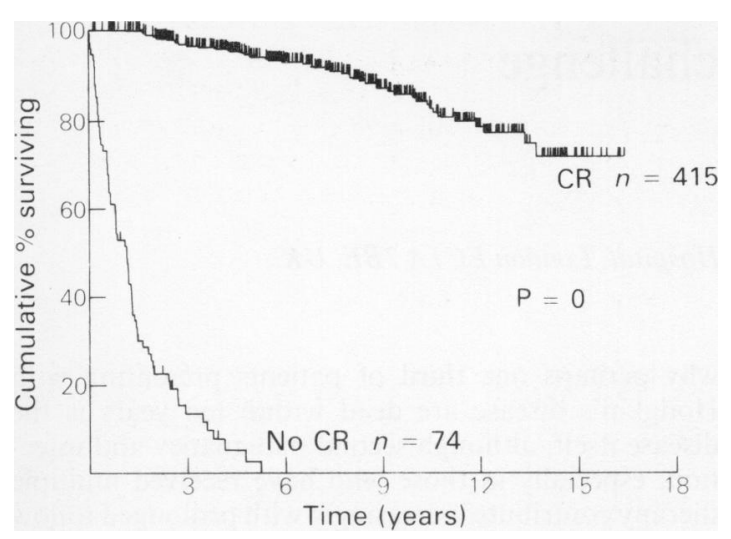

Figure 1 Hodgkin's disease all cases; survival in relation to the achievement of complete remission.

short term, be limited to modifications of radiation and chemotherapy programmes either separately or together.

It is immediately apparent that survival is worst in those patients with advanced disease for whom chemotherapy is the treatment of choice. It has been demonstrated in several series that those at highest risk of failure to enter complete remission have constitutional symptoms, very extensive disease and are older. While both constitutional symptoms and very extensive disease also correlate with the probability of recurrence, affecting survival adversely yet further, age does not (reviewed in Canellos et al., 1983). This reflects the importance of knowing why complete remission is not achieved. At St Bartholomew's Hospital only one out of fifty four patients under forty years of age failing to enter complete remission died of infectious complications during therapy, whereas this accounted for death in ten out of forty eight patients over 40. Happily treatment related mortality is still a minor problem, but as with acute leukaemia, there is no point in developing more 'intensive' (bone marrow suppressive) therapy if the patients will not be able to tolerate it.

\section{Developments in chemotherapy regimens}

The MOPP (mustine, vincristine, prednisone, procarbazine) combination, or its variants, introduced at the National Cancer Institute, Bethesda (De Vita et al., 1970), has remained the cornerstone of the treatment of advanced Hodgkin's disease. The main thrust towards improving on the results achieved with it has been towards the development of non-cross resistant combinations, which might be used alternately with MOPP, hopefully fulfilling the Goldie-Coldman hy- pothesis (Goldie \& Coldman, 1984), and thereby both increasing the complete remission rate and decreasing the frequency of relapse. Bonadonna has explored the combination of adriamycin, bleomycin, vinblastine and DTIC (dacarbazine) (ABVD). In initial studies he found an high complete remission rate with the combination in patients failing, or relapsing after MOPP (Santoro \& Bonadonna, 1979). Subsequently he conducted a comparative study in which ABVD was compared with MOPP in previously untreated patients with advanced disease. An advantage for the group of patients treated with ABVD having been demonstrated (Santoro et al., 1981), a study is now in progress in which MOPP is being compared with MOPP alternating with ABVD, which is showing a further advantage to the group treated with the two combinations (Bonadonna et al., 1984). These results are very exciting, although less success has been met with ABVD in the salvage situation at centres other than Milan. At Stanford and St Bartholomew's Hospital for example, the complete remission rate was less than twenty per cent compared with more than fifty per cent and there were very few long survivors (Krikorian et al., 1978; Sutcliffe et al., 1979). In addition, one study of using non-cross resistant combinations, not identical, but very similar to MOPP/ ABVD has shown no advantage to the combination of the two (Young et al., 1984).

\section{The treatment of localized diseases}

While there can be little argument that 'better' chemotherapy is required for patients with advanced disease (at least those with stage IIIB, IVA and IVB), there is much more controversy over how to improve treatment of localized disease. Since overall survival of patients with stage IA, IIA and IIIA disease is so good. with approximately eighty per cent alive at ten years (Timothy et al., 1978), the arguments involve not only efficacy, but toxicity and the relative risk of disease and its treatment to the patient.

The following broad statements are made about treating localised disease. Complete remission may be achieved in the vast majority of patients with either involved field irradiation, extended field irradiation or chemotherapy. Large volume disease, particularly in the mediastinum and constitutional symptoms present the greatest problem. The site of recurrence, and the frequency with which it occurs decreases with the 'amount' of treatment given.

Least dispute exists over the fact that a mediastinal mass of greater than one third of the transthoracic diameter causes a risk of recurrence of at least forty per cent by five years if 'mantle irradiation' alone is given. Most investigators consider that this is an unacceptably high relapse rate and that 'more therapy', either in 
the form of lung irradiation or chemotherapy is required (Lee et al., 1980; Prosnitz et al., 1980; Mauch et al., 1978; Hoppe et al., 1982; Dorreen et al., 1984).

With lesser volume of tumour, enthusiasm for giving more than extended field irradiation reflects the philosophy of the physician in question. Those in favour of 'more' therapy argue that longer follow up of patients will show that improved freedom from recurrence will ultimately yield improved survival. Those against this approach argue that major toxicity increases with either adding chemotherapy to, or even substituting it for irradiation, and that the majority of patients relapsing after radiotherapy failure will be able to be salvaged anyway (even if this group is at the highest risk of life threatening toxicity). Demonstrating differences even between the two extremes in terms of real patient advantage will be very difficult and involves both subjective evaluation of toxicity and also the role of laparotomy.

\section{The current place of staging laparotomy}

The application of either of the two extreme positions in relation to 'minimum' or 'maximum' therapy calls into question the role of laparotomy with lymph node mapping and splenectomy. This was introduced into the investigation of Hodgkin's disease in the nineteen sixties at Stanford. It allowed for the pathological staging of the disease within the abdomen, and provided the only method of assessing splenic involvement. At Stanford (Glatstein et al., 1969), St Bartholomew's Hospital, London (Sutcliffe et al., 1976), and elsewhere (Prosnitz et al., 1972; Cooperman et al., 1978; Smithers, 1973; Sandusky et al., 1978) it was shown that the spleen might be normal in size, but be involved, and conversely that it might be enlarged and not involved. Clinically undetected splenic involvement was found in approximately one third of patients. The widespread use of total nodal irradiation for nodal disease on both sides of the diaphragm without constitutional symptoms, and reluctance of many radiotherapists to irradiate the spleen for fear of renal damage, led to the inevitable incorporation of laparotomy into the routine staging of all patients for whom radiotherapy alone was considered to be the treatment of choice (i.e. all those with stages I, IIA and IIIA disease).

During the last five years there has been a remarkable decline in the use of laparotomy prior to the institution of therapy based on the following. Were all patients, even with very localized disease, to be treated with chemotherapy, or radiotherapy to include the spleen, it would not be necessary to know if the spleen was involved or not (in order to determine whether systemic therapy was appropriate). Conversely, were patients to be treated with extended field irradiation on the basis of clinical stage in the belief that the majority of those who would relapse because of occult splenic involvement could be salvaged with chemotherapy, the procedure would also be unnecessary. The only remaining indication for it would be a belief that splenectomy was of therapeutic benefit.

\section{Toxicity of chemotherapy}

Implicit in the planning of the optimal (most effective, least toxic, cheapest) treatment is the assumption that chemotherapy has more serious toxic side effects than irradiation and that it should be avoided until the risk of the disease becomes unacceptably high. Both infertility and the development of second malignancy undoubtedly occur more frequently with conventional chemotherapy for Hodgkin's disease (MOPP or its variants) than they do with radiation alone.

Male infertility has been reported as being inevitable following cyclical chemotherapy with both the MOPP and MVPP (mustine, vinblastine, procarbazine, prednisone) programmes, with recovery if it occurs being very late and then only partial (Chapman et al., 1981; Waxman et al., 1982; Whitehead et al., 1983). Very few children have been fathered by patients with Hodgkin's disease treated in this way with approximately six cycles of therapy. Female infertility is also common, and is manifest by a premature menopause (Chapman et al., 1979; Waxman et al., 1982; Horning et al., 1981). The frequency with which this occurs correlates with the age of the patient at presentation, those under the age of twenty five having approximately a fifty per cent chance of retaining fertility at least for some time, with this being very rare in those over thirty. It has been clearly shown that the infertility in both men and women is due to primary gonadal failure. Sperm storage prior to therapy has been advocated as a way of circumnavigating this side effect for the men. As an overall solution it is not satisfactory however, for several reasons: first, a third of the patients will be azoospermic before any chemotherapy is given; second, some patients are unable to provide the sperm and third, the amount stored, in any event, is only enough for limited attempted artificial insemination. An alternative approach, prompted by anecdotal evidence, that menstruation returned more frequently in female patients receiving the contraceptive pill than others, is to 'down regulate' the gonads with supra-active analogues of luteinizing hormone releasing hormone (LHRH) for the duration of treatment. This might theoretically protect the gonads from the effect of the chemotherapy. This is being investigated at present.

There is an undoubted increased risk of myelogenous leukaemia, and possibly also of other tumours in patients treated with the MOPP programme and its 
variants (Canellos et al., 1975; Coleman et al., 1977; Toland et al., 1978; Valagussa et al., 1981; Boivin \& Hutchinson, 1981; Nelson et al., 1981; Waxman et al., 1984; Coltman et al., 1982). There is some evidence to suggest that there is also a small risk from radiotherapy (Boivin \& Hutchinson, 1984; da Cunha et al., 1984). The risk appears to be highest in those receiving radiotherapy followed by an interval and then chemotherapy. Clearly the most satisfactory answer to the problem for both major long term side effects is the development of systemic therapy without toxicity. Bonadonna et al. (1984) as shown above, have reported that ABVD is at least as effective as MOPP. In addition, at the present the incidence of both infertility and second malignancy is very considerably lower in patients receiving this programme than in those receiving MOPP. However, it must not be neglected that adriamycin is cardiotoxic and bleomycin toxic to the lung. It will be extremely interesting to observe the long term toxicity of the 'alternating non cross resistant (e.g. MOPP, ABVD) combination programmes. The suggestion that gonadal damage of MOPP is dose related, as is that of adriamycin, allows some optimism that the alternating programmes will be less toxic (Tester et al., 1984). All the data supports the conten-

\section{References}

BOIVIN, J.F. \& HUTCHINSON, G.B. (1981). Leukemia and other cancers after chemotherapy for Hodgkin's disease. Journal of the National Cancer Institute. 67, 751.

BOIVIN, J.F. \& HUTCHISON, G.B. (1984). Radiation Carcinogenesis: Epidemiology and Biological Significance. Boice, J.D., Fraumeni, J.F. (eds) pp. 181 - 198, Raven Press, New York.

BONADONNA, G., VIVIANI, S., BONFANTE, V., VALGUSSA, P. \& SANTORO, A. (1984). Alternating chemotherapy with MOPP/ABVD in Hodgkin's disease: updated results. Proceedings of the American Society for Clinical Oncology, 3, 254.

CANELLOS, G.P., YOUNG, R.C. \& DE VITA, V.T. (1972). Combination chemotherapy for advanced Hodgkin's disease in relapse following extensive radiotherapy. Clinical Pharmacology and Therapeutics, 13, 750.

CANELlOS, G.P., DE VITA, V.T., ARSENEAU, J.C., WANGPENG, J. \& JOHNSON, R.E.C. (1975). Second malignancies complicating Hodgkin's disease in remission. Lancet, $\mathbf{i}$, 947.

CANELlOS, G.P., COME, S.E. \& SKARIN, A.T. (1983). Chemotherapy in the treatment of Hodgkin's disease. Seminars in Hematology, 20, 1.

CHAPMAN, R.M., SUTCLIFFE, S.B. \& MALPAS, J.S. (1979). Cytotoxic induced ovarian failure in Hodgkin's disease. II. Effects on sexual function. Journal of the American Medical Association, 242, 1882.

CHAPMAN, R.M., SUTCLIFFE, S.B. \& MALPAS, J.S. (1981). Male gonadal dysfunction in Hodgkin's disease. A prospective study. Journal of the American Medical Association, $245,1323$. tion that treatment should be of as short duration as possible - though under no circumstances must the efficacy of the therapy be compromised. Better alive and sterile and at risk of acute myeloblastic leukaemia than dead.

\section{Conclusion}

In summary, a watershed has been reached in the treatment of Hodgkin's disease. Within the last fifteen years cure has become the probability for the majority of patients. Much has been learnt from prospective clinical trials about prognostic variables and the efficacy and toxicity of different treatment programmes. It is now clear that different options are appropriate for different categories of patients and that some individualization of treatment may now be considered.

It is to be hoped that in the next decade, even only with the therapeutic armamentarium available today, perhaps with reducing chemotherapy and combining it with lower dose irradiation the cure rate may be increased and the toxicity reduced.

COLEMAN, N., WILLIAMS, C.J., FLINT, A., GLATSTEIN, E.J ROSENBERG, S.A. \& KAPLAN, H.S. (1977). Hematologicneoplasia in patients treated for Hodgkin's Disease. New England Journal of Medicine, 297, 1249.

COLTMAN, C.A. \& DIXON, D.O. (1982). Second malignancies complicating Hodgkin's disease: A southwest oncology group 10-year follow up. Cancer Treatment Reports, 66, 1023.

COOPERMAN, M., STRAIT, K., YOUNG, D. \& NEIDHART, J. (1978). Role of staging laparotomy in Hodgkin's Disease. Clinical Research, 26, 433A.

DA CUNHA, M.F., MEISTRICH, M.L., FULLER, L.M., CUNDIFF, J.H., HAGEMEISTER, F.B., VELASQUEZ, W.S., McLAUGHLIN, P., RIGGS, S.A., CABANILlAS, F.F. \& SALVADOR, P.G. (1984). Recovery of spermatogenesis after treatment for Hodgkin's disease: Limiting dose of MOPP chemotherapy. Journal of Clinical Oncology. 2, 6 , 571.

DE VITA, V.T., JR., SERPICK, A. \& CARBONE, P.P. (1970). Combination chemotherapy in the treatment of advanced Hodgkin's Disease. Annals of Internal Medicine, 73, 881.

DORREEN, M.S., WRIGLEY, P.F.M., LAIDLOW, J.M., PLOWMAN, P.N., NEUDACHIN, L., TUCKER, A.K., MALPAS, J.S., STANSFELD, A.G., FAUX, M.M.L., JONES, A.E. \& LISTER, T.A. (1984). The management of stage II supradiaphragmatic Hodgkin's disease at St. Bartholomew's Hospital. Cancer, in press.

FINZI, N.S. (1913). Radium Therapeutics, vii. London, H. Frowde.

GILBERT, R. (1939). Radiotherapy in Hodgkin's disease (malignant granulomatosis); anatomic and clinical foun- 
dations; governing principles; results. American Journal of Roentgenology, 41, 198.

GLATSTEIN, E., GUERNSEY, J.M., ROSENBERG, S.A. \& KAPLAN, H.S. (1969). The value of laparotomy and splenectomy in the staging in Hodgkin's disease. Cancer, 24, 709.

GOLDIE, J.H. \& COLDMAN, A.J. (1984). The genetic origin of drug resistance in neoplasms: implications for systemic therapy. Cancer Research, in press.

HORNING, S.J., HOPPE, R.T., KAPLAN, H.J. \& ROSENBERG, S.A. (1981). Female reproductive potential after treatment for Hodgkin's disease. New England Journal of Medicine, 304, 1377.

KAPLAN, H.S. (1962). The radical radiotherapy of regionally localised Hodgkin's disease. Radiology, 78, 553.

KAPLAN, H.S. (1982). The management of stage I-II Hodgkin's disease with irradiation alone or combined modality therapy: The Stanford experience. Blood, 59, 455 .

KRIKORIAN, J.G., PORTLOCK, C.S. \& ROSENBERG, S.A. (1978). Treatment of advanced Hodgkin's disease with adriamycin, bleomycin, vinblastine and imidazole carboxamine (ABVD) after failure of MOPP therapy. Cancer, 41, 2107.

LEE, C.K.K., BLOOMFIELD, C.D., GOLDMAN, A.I. \& LEVITT, S.H. (1980). Prognostic significance of mediastinal involvement in Hodgkin's disease treated with curative radiotherapy. Cancer, 46, 2403.

MAUCH, P., GOODMAN, R. \& HELlMAN, S. (1978). The significance of mediastinal involvement in early stage Hodgkin's disease. Cancer, 42, 1039.

NELSON, D.F., COOPER, S., WESTON, M.G. \& RUBIN, P. (1981). Second malignant neoplasms in patients treated for Hodgkin's disease with radiotherapy or radiotherapy and chemotherapy. Cancer, 48, 2386.

PETERS, M.V. (1950). Study of survivals in Hodgkin's disease treated radiologically. American Journal of Roentgenology, 63, 299.

PROSNITZ, L.R., NULAND, S.B. \& KLIGERMAN, M.M. (1972). Role of laparotomy and splenectomy in the management of Hodgkin's disease. Cancer, 29, 44.

PROSNITZ, L.R., CURTIS, A.M., KNOWLTON, A.H., PETERS, L.M. \& FARBER, L.R. (1980). Supradiaphragmatic Hodgkin's disease: significance of large mediastinal masses. International Journal of Radiation Oncology and Biological Physics. 6, 809.

SANDUSKY, W.R., JONES, R.C.W., HORSLEY, J.S., MARSH, W.L., TILLACK, T.W., TEGTMEYER, C.J. \& HESS, C.E. (1978). Staging laparotomy in Hodgkin's disease. Annals of Surgery, 187, 485.

SANTORO, A. \& BONADONNA, G. (1979). Prolonged diseasefree survival in MOPP-resistant Hodgkin's disease after treatment with adriamycin, bleomycin, vinblastine and decarbazine (ABVD). Cancer Chemotherapy and Pharmacology, 2, 101.

SANTORO, A., BONADONNA, G., BONFANTE, V. \& VALAGUSSA, P. (1981). Alternating drug combinations in the treatment of advanced Hodgkin's disease. New England Journal of Medicine, 306, 770.
SANTORO, A. (1984). Alternating chemotherapy with MOPP/APVD in Hodgkin's disease: updated results. Proceedings of the American Society of Clinical Oncology: 3, 254.

SMITHERS, D.W. (1973). Hodgkin 's Disease. Edinburgh and London: Churchill Livingstone.

SUTCLIFFE, S.B.J.. WRIGLEY, P.F.M., SMYTH. J.F., WEBB. J.A., TUCKER. A.K., BEARD. M.E.J., IRVING. M. \& STANSFELD, A.G. (1976). Intensive investigation in management of Hodgkin's disease. British Medical Journal. 2, 1343.

SUTCLIFFE, S., WRIGLEY. P.F.M., STANSFELD. A.G. \& MALPAS, J.S. (1979). Adriamycin, bleomycin, vinblastine and imidazole carboxamide (ABVD) therapy for advanced Hodgkin's disease resistant to mustine, vinblastine, procarbazine and prednisolone (MVPP). Cancer Chemotherapy and Pharmacology, 2, 209.

SUTCLIFFE, S.B.., WRIGLEY, P.F.M., TIMOTHY, A.R., DORREEN, M.S., SHAND, W.S., STANSFELD, A.G., JONES, A.E., MALPAS, J.S. \& LISTER, T.A. (1982). Posttreatment laparotomy as a guide to management in patients with Hodgkin's disease. Cancer Treatment Reports, 66, 759.

TESTER, W.J., KINSELLA, T.J., WALLER, B., MAKUCH, R.W.. KELLEY, P.A., GLATSTEIN, E. \& DE VITA, V.T. (1984). Second malignant neoplasms complicating Hodgkin's disease: The National Cancer Institute Experience. Journal of Clinical Oncology. 2, 7, 762.

TIMOTHY, A.R., SUTCLIFFE, S.B.J., STANSFELD, A.G.. WRIGLEY. P.M.F. \& JONES, A.E. (1978). Radiotherapy in the treatment of Hodgkin's disease. British Medical Journal, 1, 1246.

TOLAND, D., COLTMAN. C. \& MOON, T. (1978). Second malignancies complicating Hodgkin's disease: The Southwest Oncology Group Experience. Cancer Clinical Trials, $1,27$.

VALAGUSSA, P., SANTORO, A., FOSSATI-BELLANI, F., FRANCHI, F. \& BONADONNA, G. (1981). Absence of treatment-induced second neoplasma after ABVD in Hodgkin's disease. Proceedings of the American Association for Cancer Research and the American Society of Clinical Oncology, 22, 197.

WAXMAN, J.H., TERRY, Y.A., WRIGLEY, P.F.M., MALPAS, J.S., REES, L.H., BESSER, G.M. \& LISTER, T.A. (1982). Gonadal function in Hodgkin's disease: long-term follow up of chemotherapy. British Medical Journal, 285, 1612.

WAXMAN, J.H., DORREEN, M.S., WRIGLEY, P.F.M. \& LISTER, T.A. (1984). Late complications of cytotoxic chemotherapy given for advanced Hodgkin's disease. 2nd Internutional Conference on Malignant Lymphoma, Lugano (in press).

WHITEHEAD, E., SHALET, S.M., BLACKLEDGE, G., TODD, I., CROWTHER, D. \& BEARDWELL, C.J. (1983). The effect of combination chemotherapy on ovarian function in women treated for Hodgkin's disease. Cancer, 52, 1, 988.

YOUNG, R.C., LONG, D.L., GLATSTEIN, E., DUFFEY, P.L., WINKLER, C.F., WIERNIK, P.H. \& DE VITA, V.T. (1984). The current status of NCl trials in Hodgkin's disease. Second International Conference on Malignant Lymphomas, Lugano. (in press). 